\title{
Repatriación en pandemia de covid-19. Encuadres de la prensa latinoamericana
}

\author{
Repatriation in covid-19 pandemic. Frames of the latin american \\ press
}

\author{
Gaete Quezada, R. ${ }^{1}$ \\ Recibido: 20-04-2021 - Aceptado: 05-08-2021 \\ https://doi.org/10.26441/RC20.2-2021-A8
}

\begin{abstract}
RESUMEN: El estudio analiza la cobertura informativa de ocho periódicos latinoamericanos sobre la crisis migratoria acontecida el año 2020 como consecuencia de la pandemia de Covid-19, que obligó a miles de migrantes a retornar forzadamente a sus países de origen, enfrentados al cierre de fronteras terrestres, marítimas y aéreas, problemática agudizada además por la pérdida de sus puestos de trabajo en los países receptores. Se desarrolla un análisis de contenido cualitativo relacionado con los encuadres informativos presentes en las noticias digitales publicadas durante los seis primeros meses desde que se declaró la pandemia a nivel global, observándose que los encuadres de atribución de responsabilidad y conflicto concentran el foco noticioso en las informaciones publicadas por los medios de comunicación incluidos en la muestra, concluyéndose que los encuadres periodísticos sobre la repatriación durante la pandemia concentraron la cobertura informativa en las acciones de los gobiernos de la Región, especialmente de los Ministerios de Relaciones Exteriores y las misiones diplomáticas de los países latinoamericanos como principales autoridades gubernamentales responsables de la repatriación, así como respecto de las informaciones relacionadas con las tensiones políticas surgidas a nivel internacional entre algunos estados latinoamericanos, respecto de la gestión del retorno de las personas que quedaron varadas en el extranjero sin poder ingresar a territorio nacional, debido a las restricciones al ingreso y libre circulación de personas impuesta por los gobiernos de la región.
\end{abstract}

Palabras clave: Covid-19; derechos humanos; migración forzada; prensa escrita; Teoría del Encuadre.

ABSTRACT: The study analyzes the news coverage of eight Latin American newspapers on the migration crisis that occurred in 2020 as a result of the Covid-19 pandemic, which forced thousands of migrants to forcibly return to their countries of origin, faced with the closure of land borders, maritime and air, problems further exacerbated by the loss of their jobs in the recipient countries. An analysis of qualitative content related to the informative frames present in the digital news published during the first six months since the pandemic was declared globally is developed, observing that the frames of attribution of responsibility and conflict concentrate the news focus on the information published by the media included in the sample, concluding that the journalistic frames on repatriation during the pandemic concentrated the news coverage on the actions of the governments of the Region, especially the Ministries of Foreign Affairs and the diplomatic missions of the countries. Latin Americans as the main governmental authorities responsible for repatriation, as well as regarding the information related to the political tensions that have arisen at the international level between some Latin American states, regarding the management of the return of the people who were left behind moved abroad without being able to enter national territory, due to restrictions on entry and free movement of people imposed by the governments of the region.

Keywords: Covid-19; human rights; written press; forced migration; Theory of Framing.

\footnotetext{
${ }^{1}$ Ricardo Gaete Quezada es Doctor en Procesos de Cambio Social por la Universidad de Valladolid y Académico Jornada Completa del Departamento de Ciencias Sociales en la Facultad de Ciencias Sociales, Artes y Humanidades de la Universidad de Antofagasta (Chile). ricardo.gaete@uantof.cl, https://orcid.org/0000-0003-2359-2304
} 


\section{Introducción}

Durante el año 2020 hemos experimentado las graves consecuencias sanitarias, sociales y económicas que el Covid-19 ha generado desde su aparición en China a finales del 2019. Desde entonces, millones de personas se han contagiado y fallecido a causa de la pandemia, lo que ha llevado a las autoridades gubernamentales y de organismos internacionales a tomar una serie de decisiones tales como el confinamiento o el toque de queda, con el propósito de favorecer el aislamiento social para enfrentar los terribles efectos que actualmente se observan a nivel mundial.

Una de las consecuencias de la pandemia en Latinoamérica fue la gran cantidad de migrantes que quedaron varados en los países de la Región debido al cierre de fronteras, lo que les impedía viajar sumado a la pérdida de sus puestos de trabajo y consecuentemente el deterioro de la situación económica de dicha población, generando una crisis migratoria con impactos sanitarios, sociales, económicos e incluso de tipo político en las relaciones internacionales entre los estados latinoamericanos.

Según estimaciones de la Organización Internacional para las Migraciones (OIM) (2020), hasta mediados de julio de 2020 aproximadamente casi 2.800 .000 migrantes a nivel mundial quedaron varados por causa del Covid-19, de los cuales 1.200 .000 corresponden a Oriente Medio y África del Norte como la zona más afectada, mientras que para el caso latinoamericano la estimación de varados por la pandemia a dicha fecha era casi 150.000 personas. La propia OIM señala en su informe que dichas cifras “...incluyen varias categorías de población, independientemente de su estatus legal, que quedaron varadas debido a Covid-19 y/o necesitan algún tipo de asistencia” (p.10).

Así, la pandemia por Covid-19 declarada por la Organización Mundial de la Salud (OMS) a partir del 11 de marzo de 2020, se ha transformado en un innegable hecho noticioso de gran interés para las audiencias mundiales, asignándole relevancia a la manera en la cual se redactan las noticias y las perspectivas que los medios de comunicación otorgan a las informaciones para sus audiencias. Por ello, como señalan Ortiz y Stable (2021, p.176) la comunicación sanitaria eficaz se transforma en “...un factor importante en la forma en que las autoridades internacionales y nacionales están abordando esas epidemias y pandemias, cuyas consecuencias para las poblaciones vulnerables dependen en parte, de la eficacia de las comunicaciones sobre riesgos para la salud", por lo que los medios de comunicación a nivel mundial tienen un rol clave en las estrategias sanitarias para enfrentar la actual pandemia de Covid-19.

Por lo anteriormente expuesto, el artículo intenta responder a la siguiente interrogante: ¿Cuáles son los encuadres noticiosos de los periódicos latinoamericanos sobre la repatriación de migrantes durante la pandemia? A partir de dicha pregunta de investigación, se desarrolla un estudio cualitativo por el interés académico de comprender el fenómeno de la repatriación forzada de los migrantes durante la pandemia, desde la perspectiva de la prensa escrita latinoamericana considerando a los medios de comunicación como un actor relevante para enfrentar los efectos sociales de la crisis sanitaria global. Se utiliza un análisis de contenido para identificar los encuadres aplicados en las noticias digitales publicadas por periódicos pertenecientes al Grupo Diarios de América (GDA), durante los seis primeros meses de la pandemia en el año 2020, considerando la tipología de encuadres de Semetko y Valkenburg (2000).

Los resultados obtenidos evidencian un predominio de los encuadres de atribución de responsabilidad y conflicto en las noticias digitales publicadas por los diarios latinoamericanos incluidos en la muestra del estudio en el período analizado, observándose un encuadre noticioso que asigna un rol preponderante a los Ministerios o Secretarias de Relaciones Exteriores en la repatriación de los migrantes varados, informando sobre las consecuencias de la crisis humanitaria y migratoria generada por el cierre de fronteras decretado por la mayoría de las autoridades gubernamentales latinoa- 
mericanas, para proteger el territorio nacional del avance en el contagio del covid-19, postergando durante varias semanas el retorno de sus connacionales y extranjeros residentes.

\section{Marco referencial}

Desde la década de los setenta se despliega la Teoría del Encuadre (TE), como un enfoque teórico y metodológico en el campo de la comunicación con importantes raíces en el ámbito de la psicología y sociología, principalmente mediante las contribuciones de Bateson y Goffman respectivamente (Álvarez-Gálvez, Plaza, Muñiz y Lozano, 2014; Entman, 1993; Giménez y Berganza, 2009; Koziner, 2013; Piñeiro-Naval y Mangana, 2018; Sádaba, 2008; Semetko y Valkenburg, 2000; Valera, 2016).

Así, uno de los investigadores destacados por sus contribuciones a la consolidación de la TE es Robert Entman (1993), quien plantea que los encuadres no surgen exclusivamente desde los textos comunicativos, sino que es posible identificar otros lugares desde donde éstos emergen como resultado de un proceso de negociación e intercambio entre: emisor, audiencias, cultura, etc. Según Entman (1993, p.52), la TE implica “...la selección de algunos aspectos de la realidad y hacerlos más prominentes en un texto comunicativo, de manera que promuevan definiciones particulares de los problemas, interpretaciones causales, evaluaciones morales y/o recomendaciones para el tratamiento del asunto descrito".

Según Ardévol-Abreu (2015, p.425), los encuadres informativos son incorporados por cada periodista al escribir la noticia porque "...llaman la atención de algunos aspectos de la realidad en detrimento de otros, por lo que para definirlos hay que tener en cuenta tanto lo que describe como lo que omite", aludiendo de esta forma a la relevancia que tiene el rol de cada profesional de la comunicación al transmitir una noticia y la forma en la que la misma puede impactar en las audiencias y la opinión pública (Cristti et al, 2020).

En síntesis, Giménez y Berganza (2009) afirman que la TE abarca diferentes ámbitos del proceso informativo en los cuales se aplican los encuadres: el trabajo periodístico, las orientaciones políticas y económicas de los diferentes medios de comunicación como emisores de la información e incluso la relevancia de la subjetividad de los lectores o audiencias como receptores de las noticias (Álvarez-Gálvez et al, 2014; Koziner, 2013; Muñiz, 2011).

Según Mukhortikova (2018), otra perspectiva de la TE clasifica a los encuadres en dos grandes orientaciones o tendencias: los encuadres textuales y la importancia de sus funciones en el texto periodístico, que corresponden a la línea de pensamiento desarrollada por Entman (1993) y los encuadres semánticos que intentan establecer una mirada más deductiva que lo asocia con propuestas como las de Semetko y Valkenburg (2000).

Igualmente, durante la última década los flujos migratorios han aumentado significativamente a nivel mundial, debido a los efectos de diferentes crisis económicas, políticas e incluso medioambientales, obligando a los personas a dejar su lugar de origen para migrar hacia otras latitudes buscando mejores condiciones de vida. Así, uno de los movimientos migratorios analizados en la literatura es la migración forzada (MF), la que según Castillo (2020, p.18) permite analizar sus: 1) causas histórico/estructurales, 2) dinámicas de tránsito irregular de los migrantes en situaciones de clara vulnerabilidad y 3) procesos de violencia que afectan a los migrantes relacionadas con la falta de garantías y de respeto a los derechos humanos.

Según la OIM (2019, p.126), la MF describe un "movimiento migratorio que, si bien puede estar propiciado por diversos factores, entraña el recurso a la fuerza, la coacción o la coerción". Más adelante, en el mismo glosario de la OIM se describe el concepto de "migración por motivos ambientales", entendido como: 
Movimiento de personas o grupos de personas que, debido principalmente debido a cambios repentinos y graduales en el medio ambiente que inciden negativamente en sus vidas o en sus condiciones de vida, se ven obligados a abandonar su lugar de residencia habitual, o deciden hacerlo, con carácter temporal o permanente, y se desplazan a otras partes de su país de origen o de residencia habitual, o fuera del mismo (p.129).

De acuerdo con Márquez y Delgado (2011), la MF está relaciona con “...la necesidad de acceder a medios de subsistencia u oportunidades de movilidad social, vastos sectores de la población son literalmente expulsados de sus territorios para desplazarse dentro del propio país o hacia el extranjero" (p.20), considerando las características expuestas en la Figura 1 que van configurando una nueva división del trabajo, acentuando la precarización derivada del proceso de globalización neoliberal.

Figura 1. Características migración forzada

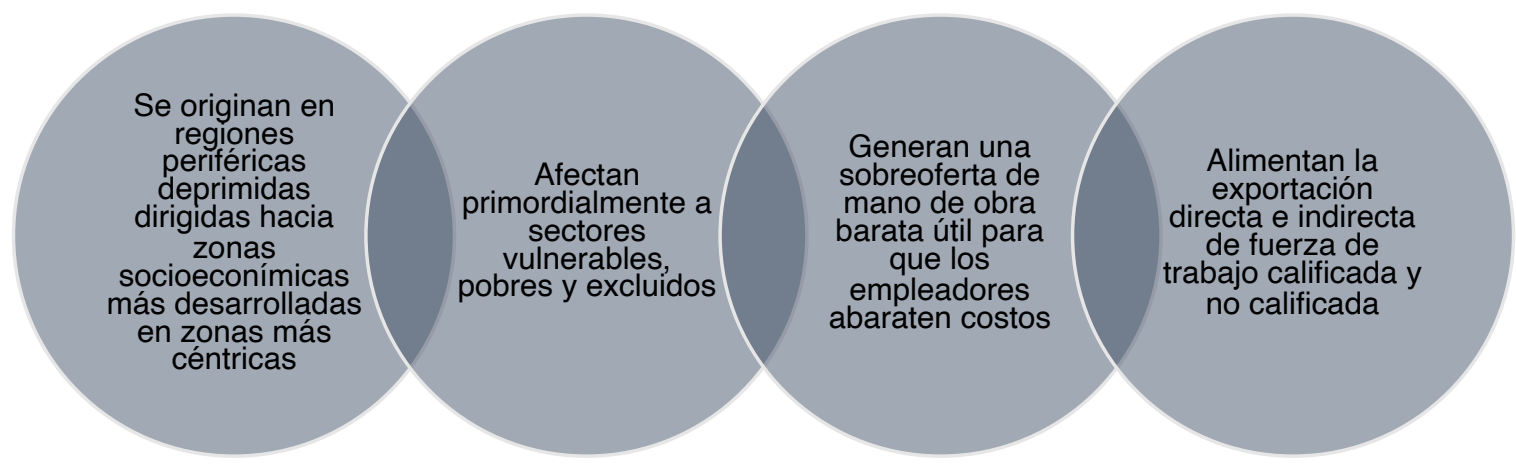

Elaboración propia, basado en Márquez y Delgado, (2011).

En el contexto planteado anteriormente, la MF puede desarrollarse por diferentes causas: catástrofes naturales, conflictos sociopolíticos y culturales, criminalidad y narcotráfico, tráfico de personas, expropiación de territorios y recursos naturales, exclusión social, desempleo, pobreza, exceso de recurso humano sobre calificado (Castillo, 2020; Márquez y Delgado, 2011).

En cualquiera de los tipos de MF, la vulneración de los derechos humanos de los migrantes está permanentemente presente, debido a que las personas no encuentran en su lugar de origen los medios para asegurar un adecuado desarrollo humano, debiendo movilizarse forzosamente hacia otros territorios dentro o fuera de su país, buscando mejores condiciones de vida (Abuelafia, 2020; Castillo, 2020; Celis y Aierdi, 2015; CEPAL, 2020; Gaete, 2021).

Sin embargo, al conjunto de causas o tipos de MF identificadas previamente, es necesario actualmente agregar aquella ocasionada por los efectos derivados de la crisis sanitaria ocasionada por la pandemia de Covid-19 a nivel mundial, desarrollada desde finales de 2019 a la fecha (Abuelafía, 2020; CEPAL, 2020; Gaete, 2021; Matarín, 2020).

En dicho contexto, miles de migrantes de países latinoamericanos se vieron obligados a retornar forzosamente a sus lugares de origen durante el año 2020, apremiados por la pérdida de sus puestos de trabajo y por el cierre de fronteras aéreas y terrestres implementado como medida gubernamental para controlar los contagios ocasionados por la pandemia (Gaete, 2021), expuestos a vulneraciones de sus derechos humanos y a la incertidumbre generada por la falta de respuestas concretas de parte de los gobiernos latinoamericanos a las solicitudes de apoyo para facilitar el retorno (Abuelafia, 2020; Gaete, 2021). 


\section{Metodología}

Para responder la pregunta de investigación que orienta nuestro estudio se utilizó un diseño cualitativo de investigación, basado en la revisión de las noticias publicadas por los periódicos latinoamericanos pertenecientes al consorcio Grupo de Diarios América (GDA).

Además, la perspectiva cualitativa de la TE de acuerdo con Valera (2016), permite obtener “... una comprensión suficiente de la construcción del discurso público y mediático" (p.19), por lo que nuestro estudio tiene como objetivo principal identificar los encuadres periodísticos de los medios de prensa escrita latinoamericanos sobre la repatriación de migrantes durante la pandemia.

Así, la muestra del estudio está integrada por ocho diarios identificados en la Tabla 1, considerando como criterios de inclusión en la muestra: 1) Pertenecer al grupo GDA; 2) tener edición en español; 3) poseer versión online o digital y 4) permitir acceso gratuito al texto completo de las noticias publicadas.

Tabla 1. Diarios latinoamericanos incluidos en el estudio

\begin{tabular}{|l|c|c|l|}
\multicolumn{1}{c|}{ Diario } & País & Primera publicación & \multicolumn{1}{c|}{ Sitio web } \\
\hline El Comercio & Perú & 04 de mayo de 1839 & $\underline{\text { https://elcomercio.pe/ }}$ \\
\hline El Mercurio & Chile & 01 de junio de 1900 & $\underline{\text { https://www.emol.com/ }}$ \\
\hline El Nacional & Venezuela & 03 de agosto de 1943 & $\underline{\text { https://www.elnacional.com/ }}$ \\
\hline El Tiempo & Colombia & 30 de enero de 1911 & $\underline{\text { https://www.eltiempo.com/ }}$ \\
\hline El País & Uruguay & 14 de septiembre de 1918 & $\underline{\text { https://www.elpais.com.uy/ }}$ \\
\hline El Universal & México & 01 de octubre de 1916 & $\underline{\text { https://www.eluniversal.com.mx/ }}$ \\
\hline La Nación & Argentina & 04 de enero de 1870 & $\underline{\text { https://www.lanacion.com.ar/ }}$ \\
\hline La Prensa Gráfica & El Salvador & 10 de mayo de 1915 & $\underline{\text { https://www.laprensagrafica.com/ }}$ \\
\hline
\end{tabular}

Elaboración propia.

Además, el período analizado incluye las noticias digitales relacionadas con la repatriación de migrantes publicadas en los sitios web de cada uno de los diarios identificados en la Tabla 1, durante los seis primeros meses desde que fuera declarada la pandemia por la OMS el 11 de marzo de 2020, específicamente para aquellas informaciones relacionadas con la repatriación publicadas entre el 25 de marzo y el 30 de septiembre de 2020. Se opta por analizar solo las noticias digitales publicadas por los diarios pertenecientes al grupo GDA, descartando las editoriales, cartas al director, etc., replicando los criterios expuestos por el trabajo de Muñiz (2011), en cuanto a la constante actualización de la información y mayor comodidad para la localización y selección de las noticias digitales incluidas en la muestra del estudio.

El estudio desarrolla un análisis de contenido cualitativo, considerando la perspectiva del encuadre o framing periodístico (Ardévol-Abreu, 2015; Gronemeyer y Porath, 2017; Muñiz, 2011), para examinar los principales aspectos de cada noticia sobre la repatriación de ciudadanos latinoamericanos durante la pandemia, utilizando la tipología de encuadres expuesta en la Figura 2 (Fernández y Corral, 2016; Gaete, 2021; Muñiz, 2011; Semetko y Valkenburg, 2000). 
Figura 2. Encuadres noticiosos del fenómeno de repatriación durante la pandemia
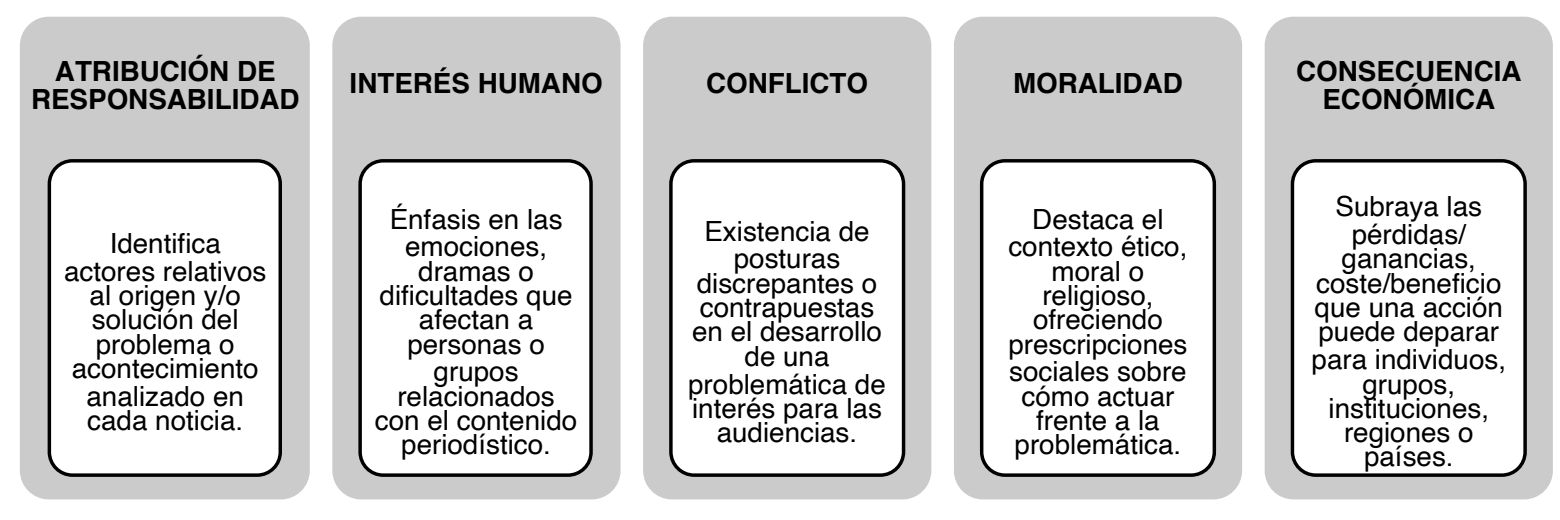

Basado en Semetko y Valkenburg (2000) y Gaete (2021).

Los cinco encuadres incluidos en la Figura 2 fueron propuestos originalmente por Semetko y Valkenburg (2000), siendo frecuentemente utilizados por los estudios e investigaciones que analizan los encuadres noticiosos de la prensa a nivel mundial en diferentes contextos sociales y disciplinares (Cristti et al, 2020; Fernández y Corral, 2016; Gaete, 2021; Gonzáles, 2016; Gronemeyer, 2017; Muñiz, 2011). Según Gronemeyer (2017), los cinco encuadres propuestos por Semetko y Valkenburg son fácilmente replicables a muestras más o menos extensas, en estudios longitudinales y en diferentes contextos culturales. Una apreciación similar expresa Muñiz (2011), quien señala que dicha propuesta de encuadres es un ejemplo de la perspectiva deductiva de la TE, identificando enfoques informativos que permiten el análisis de contenido de las noticias estudiadas.

El procedimiento de recolección de la información utilizado en el estudio se realizó mediante la búsqueda de las noticias digitales relacionadas con la migración en los motores de búsqueda disponible en los sitios web de cada diario latinoamericano incluido en el estudio, considerando como palabras clave para orientar las búsquedas: 1) migración, 2) migrantes y 3) repatriación. Posteriormente, los resultados obtenidos fueron filtrados por fecha de publicación, incluyendo finalmente en la muestra únicamente a las noticias publicadas entre marzo y septiembre de 2020, excluyendo a las editoriales, cartas al director $\mathrm{u}$ otro tipo de apartados disponibles en cada periódico.

El presente estudio es de tipo exploratorio cualitativo, por lo que para analizar cada noticia relacionada con la repatriación no se consideró la participación de otros codificadores, se elaboró una base de datos en MS EXCEL para identificar el título de cada nota periodística, la fecha de publicación, el periódico que contiene la noticia, el encuadre noticioso predominante y el enlace de Internet desde el que se recupera la información. Posteriormente, en cada artículo periodístico se identifican incidentes que tengan significación en sí mismos para identificar cada encuadre, considerando al párrafo como extensión máxima para su identificación dentro de los textos analizados, que describen los principales aspectos de cada encuadre noticioso sobre la repatriación, mediante un análisis de contenido cualitativo de las noticias sobre la migración incluidas en la muestra (Álvarez-Gálvez et al., 2014; Gonzáles, 2016; Gronemeyer, 2017; Muñiz, 2011).

\section{Resultados}

La Tabla 2 presenta la distribución del total de 88 noticias digitales sobre la repatriación que constituyen la muestra no probabilística por conveniencia, que fueron publicadas en los diarios incluidos en el estudio durante los primeros seis meses de la crisis sanitaria por Covid-19, según el procedimiento de búsqueda expuesto anteriormente en la metodología del trabajo. 
Tabla 2. Distribución de los encuadres periodísticos sobre la repatriación en la prensa latinoamericana

\begin{tabular}{|l|c|c|c|c|c|c|}
\multicolumn{1}{c}{$\begin{array}{c}\text { Diario / } \\
\text { Encuadre }\end{array}$} & $\begin{array}{c}\text { Atribución de } \\
\text { Responsabilidad }\end{array}$ & $\begin{array}{c}\text { Interés } \\
\text { Humano }\end{array}$ & Conflicto & Moralidad & $\begin{array}{c}\text { Consecuencia } \\
\text { Económica }\end{array}$ & \begin{tabular}{c} 
Total \\
\hline El Comercio
\end{tabular} \\
\hline El Mercurio & 5 & 2 & 5 & 1 & 0 & 13 \\
\hline El Nacional & 2 & 1 & 0 & 0 & 0 & 8 \\
\hline El Tiempo & 3 & 2 & 10 & 1 & 0 & 15 \\
\hline El País & 5 & 1 & 3 & 2 & 0 & 9 \\
\hline El Universal & 5 & 0 & 2 & 1 & 1 & 9 \\
\hline La Nación & 3 & 0 & 0 & 3 & 1 & 9 \\
\hline La Prensa Gráfica & 3 & 2 & 8 & 1 & 2 & 14 \\
\hline Total & 33 & 8 & 32 & 9 & 2 & 11 \\
\hline
\end{tabular}

Elaboración propia.

Además, desde la perspectiva de los encuadres periodísticos considerados en nuestro estudio, la "Atribución de Responsabilidad" con 38\% y el "Conflicto" con el 36\%, son los encuadres que concentran la mayor cantidad de noticias publicadas sobre la repatriación en Latinoamérica durante la pandemia.

Asimismo, El Nacional de Venezuela es el periódico que publicó más noticias relacionadas con la repatriación durante el período analizado, concentrando la mayoría de ellas en el encuadre relacionado con el conflicto generado por las demandas de retorno de los ciudadanos latinoamericanos, especialmente de los venezolanos.

Tabla 3. Categorías de análisis

\begin{tabular}{|c|c|c|}
\hline \multirow{4}{*}{ Categoría Central } & Categorías & Subcategorías \\
\cline { 2 - 2 } & $\begin{array}{c}\text { Atribución de } \\
\text { responsabilidad }\end{array}$ & Actores gubernamentales \\
\cline { 2 - 3 } $\begin{array}{c}\text { Encuadres noticiosos } \\
\text { de la repatriación }\end{array}$ & Interés humano & Acciones gubernamentales \\
\cline { 2 - 3 } & Conflicto & Características o acciones personales \\
\cline { 2 - 3 } & Moralidad & Individuos, grupos o países en conflicto \\
\cline { 2 - 3 } & Identificación de ganadores o perdedores \\
\cline { 2 - 3 } & Interés Económico & Principios religiosos o prescripciones sociales \\
\cline { 2 - 3 } & $\begin{array}{r}\text { Pérdidas/Ganancias financieras } \\
\text { Costos/Gastos involucrados }\end{array}$ \\
\hline
\end{tabular}

Elaboración propia, basado en Semetko y Valkenburg (2000).

La Tabla 3 identifica las categorías de análisis utilizadas para examinar los textos de las noticias incluidas en el estudio, considerando los indicadores de los encuadres propuestos por Semetko y Valkenburg (2000).

\subsection{Atribución de Responsabilidad}

Según Semetko y Valkenburg (2000), los principales indicadores para reconocer este encuadre son la identificación de niveles gubernamentales o institucionales capaces de solucionar el problema o que tienen relación con su aparición, así como las acciones requeridas para solucionar la problemática analizada. 
En las noticias examinadas, uno de los actores más relevantes en los procesos de repatriación de migrantes durante la pandemia de COVID-19 del año 2020, fueron los Ministerios de Relaciones Exteriores de los países latinoamericanos:

La Secretaría de Relaciones Exteriores, en coordinación con el Ministerio de Relaciones Exteriores de Brasil, llevaron a cabo una misión humanitaria para devolver connacionales a cada una de las dos naciones. "Las repatriaciones se hicieron mediante un vuelo chárter contratado por el gobierno brasileño en la ruta Ciudad de México-Panamá-Sao Paulo-Panamá-Ciudad de México, con el apoyo del gobierno de Panamá y en estricto apego a las disposiciones sanitarias y de seguridad de esos tres países» (El Universal, 25 de abril de 2020)

A través de Cancillería se ha identificado que son un grupo de 1.100 peruanos que desea retornar al país. En estos días de la presente semana deben retornar vía Arica, manifestó el primer ministro. Zeballos agregó que se están ultimando las coordinaciones con la Cancillería chilena sobre los procesos técnicos para la repatriación, como las pruebas de coronavirus, el transporte o una eventual cuarentena si algún compatriota resultara positivo para COVID-19 (El Comercio Perú, 30 de junio de 2020)

Asimismo, la cobertura periodística reconoce como otro de los actores relevantes para la repatriación de latinoamericanos durante la pandemia a las Embajadas y Consulados:

¿Cómo traer de regreso a Bogotá, en plena pandemia, con fronteras cerradas, a cerca de 400 colombianos, en situación vulnerable, repartidos en 19 países de Europa y el sudeste asiático? Ese fue el desafío que se planteó el embajador colombiano en Indonesia, Juan Camilo Valencia. Era, sin duda, el mayor reto de su gestión diplomática [...] decidió armar un equipo junto a sus colegas embajadores de Tailandia, Singapur, Vietnam y Malasia, además de Australia, quienes compartían su misma preocupación (Quintero, 17 de mayo de 2020)

Los diplomáticos peruanos realizaron coordinaciones con las autoridades migratorias chilenas con la finalidad de que la revisión de los documentos necesarios para el viaje entre Arica y Tacna se hagan en el Terminal Internacional de Arica, y no en el puesto de control chileno en la frontera. Los buses partirán hasta el Complejo Fronterizo Santa Rosa, en Tacna, donde realizarán el control migratorio peruano (Suárez, 22 de mayo de 2020)

También, la colaboración entre los Gobiernos nacionales de los países latinoamericanos adquiere un papel fundamental en los procesos de repatriación de inmigrantes:

Una segunda videoconferencia con los Presidentes de países miembros y observadores de Prosur, encabezó este lunes el Mandatario Sebastián Piñera, esto con el fin de evaluar las acciones desplegadas y coordinar nuevos esfuerzos regionales contra el combate del coronavirus. En la instancia, se acordó profundizar la coordinación de los distintos países para tener una colaboración efectiva en la lucha contra el covid-19, a la vez que se trabajará en la repatriación de nacionales (Romero, 06 de abril de 2020)

Debo agradecer al canciller chileno y al pueblo de Chile por la estrecha, solidaria y fructífera cooperación en la repatriación de ciudadanos bolivianos" [...] Asimismo, destacó que "todos los países de la región enfrentamos la pandemia y tenemos muchos desafíos por delante. Entendiendo la dimensión global del covid-19, las autoridades de la región nos colaboramos activamente en distintas áreas: desde repatriaciones hasta intercambio de información (Vargas, 08 de junio de 2020)

En síntesis, el rol desempeñado por las autoridades gubernamentales en la implementación de soluciones a la crisis migratoria derivada de la pandemia por Covid-19, es un encuadre importante de las noticias relacionadas con las repatriaciones de ciudadanos latinoamericanos durante el año 2020, confirmando que las acciones y decisiones gubernamentales respecto de la población migrante son un foco de atención importante y permanente para los medios de comunicación latinoamericanos, respecto de las políticas migratorias y las decisiones administrativas frente a los flujos migratorios que ingresan a cada país (Abuelafía, 2020; Gaete, 2021; Matarín, 2020; Muñiz, 2011, Stang et al, 2020; Stefoni y Brito, 2019). 


\subsection{Interés humano}

Según Semetko y Valkenburg (2000), los encuadres noticiosos en este ámbito presentan como aspectos distintivos a la identificación y descripción de individuos o grupos, así como sus características o situaciones personales como foco informativo, destacando las informaciones sobre las condiciones, sentimientos, emociones o estados de ánimo de quienes protagonizan cada noticia.

Así, uno de los hechos que concitaron el interés humano en la cobertura periodística fueron las "acampadas" de cientos de personas en las inmediaciones de sus embajadas o consulados, solicitando ser repatriados a sus países de origen:

La escena de ciudadanos bolivianos que acampan en una plaza afuera de su consulado en Providencia [Chile] esperando ser repatriados, ha marcado estas últimas dos semanas. Anoche seguía esperando en una jornada marcada por las bajas temperaturas y probables chubascos: de hecho algunas gotas cayeron. Las autoridades del país vecino han enfatizado que no los dejarán ingresar hasta que cumplan la cuarentena que exige el protocolo sanitario del covid-19 (Peña, 03 de junio de 2020)

Duermen en carpas a las afuera de la embajada de Colombia en Santiago de Chile. Durante las noches, la temperatura suele llegar a los 12 grados centígrados. Y en las madrugadas, baja hasta los 9 . Así han vivido en los últimos días cerca de 200 colombianos que esperan un vuelo humanitario para regresar al país. La mayoría están en situación de calle y pasan la noche en cambuches improvisados a las afueras del edificio. Otros duermen en albergues o en la casa de alguien que les presta una cama. Hay personas de todas las edades: desde bebés que no han cumplido su primer año de vida hasta adultos mayores (Reyes, 03 de junio de 2020)

El rápido deterioro de la situación socio-económica de miles de migrantes latinoamericanos se tradujo en una exposición a condiciones humanitarias precarias, que sobrepasaron rápidamente la capacidad de reacción de los países receptores, exponiendo a las personas varadas a condiciones que se contraponen con los derechos humanos de los y las migrantes (Abuelafia, 2020; Celis y Aierdi, 2015; Gaete, 2021), debiendo dormir por varias semanas en las calles a las afueras de sus embajadas en improvisados campamentos, sin trabajo estable ni servicios básicos o acceso a los sistemas sanitarios locales.

En este tipo de informaciones, tal y como plantean Semetko y Valkenburg (2000) en su propuesta, resulta importante observar que se incluyeron imágenes, vídeos y breves grabaciones de relatos de los migrantes protagonistas de las noticias, incorporando recursos visuales y auditivos digitales como complemento de la redacción de la noticia desarrollada por los/las periodísticas responsables de la indagación, otorgando un contexto más gráfico y empático con la realidad social descrita.

También, según las noticias relacionadas con este encuadre, una de las características de las repatriaciones forzadas acontecidas en Latinoamérica durante la pandemia, es que se trataba de personas que no pudieron cruzar las fronteras hacia sus países, producto de lo cual paulatinamente se fueron quedando sin recursos económicos para poder subsistir:

Cinco meses ya han pasado, desde el decreto de aislamiento y el cierre de fronteras en Argentina, meses en los cuales cientos de venezolanos varados en el país, han debido recurrir a su ingenio o a la caridad de amigos, conocidos e instituciones y organizaciones, para poder sobrevivir, en medio de una realidad en pausa, sin hogar, sin empleo, y muchas veces sin familia o conocidos. Muchos llegaron en verano, y han debido hacerle frente al frío del invierno, sin abrigos, ni ropa adecuados para ellos (Flores, 19 de agosto de 2020)

Nos inscribimos en el consulado para ponernos en el vuelo que nos debería llevar a casa, pensamos que iba a ser muy rápido. De hecho, cuando llegamos a República Dominicana nos hicimos la prueba del covid-19. Nos estamos quedando en una habitación, es un país muy caro, cada vez uno cuenta con menos recursos, y además hay que guardar porque sabemos que el vuelo que nos llevará de regreso a casa no 
será gratis, que hay que hacerse la PCR, que hay que cumplir una cuarentena en Caracas (De Jesús, 03 de septiembre de 2020)

El cierre de fronteras terrestres y aéreas generó un tiempo de espera importante para concretar las repatriaciones, lo que sumado a los efectos del Covid-19 en la pérdida de puestos laborales de los migrantes (Abuelafía, 2020; Matarín, 2020), ocasionó un fuerte impacto en la situación socioeconómica de miles de ciudadanos latinoamericanos durante la pandemia, especialmente porque no se trató de un proceso migratorio voluntario (Celis y Aierdi, 2015; Gómez-Johnson, 2015), sino más bien un desplazamiento forzado por la crisis sanitaria que los obligaba a retornar a sus países de origen.

El deterioro de la situación socio-económica y sanitaria de quienes esperaban ser repatriados, se transforma en una perspectiva importante para las noticias relacionadas con este encuadre, permitiendo a las audiencias dimensionar con mayor empatía el drama humanitario generado por la pandemia para los migrantes.

\subsection{Conflicto}

En este tercer encuadre propuesto por Semetko y Valkenburg (2000), el énfasis está centrado en los desacuerdos, reproches o disputas que puedan surgir entre dos o más individuos, grupos o países respecto de una situación o problema, así como la existencia de sentimientos hacia ganadores o perdedores de la disputa.

En ese contexto, las repatriaciones en Latinoamérica se caracterizaron por estar relacionadas con denuncias presentadas ante diferentes Organismos Internacionales:

Un sector de la oposición presentó hoy un reclamo ante la Comisión Interamericana de Derechos Humanos $(\mathrm{CIDH})$ con el objetivo de alertar sobre la situación de los varados [...] aseguran que los argentinos viven en una situación de "precariedad" y de "enorme riesgo para su vida, salud e integridad física". Los legisladores reclamaron "la adopción de medidas urgentes, en atención al paulatino y sistemático deterioro de las condiciones de vida y el ejercicio de los más elementales derechos de los argentinos varados en el exterior (Soria, 22 de abril de 2020)

La Fundación Nacional para el Desarrollo (FUNDE) solicitó medidas cautelares a la Comisión Interamericana de Derechos Humanos (CIDH) el pasado 9 de julio. La medida se tomó para solicitar amparo para los salvadoreños que se encuentran varados en el extranjero. Un número no identificado de salvadoreños se encuentran varados en diferentes partes del mundo por más de cuatro meses, muchos viviendo en condiciones precarias. La vida, salud e integridad de estas personas se ve amenazada, debido a que el Gobierno de El Salvador les impide el retorno a su nación (La Prensa Gráfica, 27 de julio de 2020)

En otros casos, los organismos internacionales se transformaron en actores que advirtieron las precarias condiciones en la que se encuentran diferentes colectivos latinoamericanos:

La OEA advirtió que el cierre intermitente y arbitrario de la frontera por parte del régimen de Nicolás Maduro, ha agravado la situación de vulnerabilidad de las personas que esperan regresar a su país, configurando la sistematización de violaciones a sus derechos humanos (El Nacional, 10 de septiembre de 2020)

La semana pasada, unos 452 venezolanos varados en Panamá por el cierre de las fronteras aéreas pidieron a través de una carta a la ONU que mediara para que el régimen de Venezuela autorizara un vuelo humanitario de retorno, el cual estaban gestionando sin éxito desde hacía meses (El Nacional, 21 de septiembre de 2020)

Una de las situaciones relevantes de los procesos de migración forzada acontecida durante la pandemia, fueron los recursos judiciales interpuestos por los migrantes frente a las acciones guber- 
namentales implementadas para contener los contagios por Covid-19. En El Salvador, un grupo ciudadanos salvadoreños varados en el extranjero interpuso un recurso de Amparo por el Plan de Repatriación presentado por el Gobierno:

La nueva orden del tribunal constitucionalista fue tomada el miércoles pasado, pero dada a conocer ayer a través de otra resolución, como parte del proceso que inició el 8 de abril anterior con la admisión de una demanda de amparo interpuesta por ciudadanos que no han podido regresar a El Salvador por el cierre del aeropuerto nacional. Son más de 4,800 connacionales que están varados en otros países, según Cancillería (Hernández, 09 de mayo de 2020)

La Sala de lo Constitucional de la Corte Suprema de Justicia (CSJ) calificó de inadmisible el plan de repatriación que presentó el Gobierno que solamente incluye a 1,200 salvadoreños que tenían planificado regresar a El Salvador antes del 17 de marzo en un plazo de 14 semanas (2 meses y medio). La Sala ordenó al Gobierno que presente un plan en el que el plazo sea reducido a "uno que resulte razonable" y que incluya a todos los salvadoreños que han manifestado su intención de retornar al país (Calderón, 25 de mayo de 2020)

Otro caso de judicialización presente en las noticias relacionadas con la repatriación, afecta a los ciudadanos colombianos residentes en Chile y Ecuador respectivamente:

Cerca de 350 colombianos que llevan un mes acampando delante del Consulado General de su país en Santiago de Chile y unos 50 ecuatorianos ya habrían suscrito las condiciones del Gobierno chileno [...] La Coordinadora Nacional de Inmigrantes presentó un recurso de amparo a la Corte de Apelaciones de Santiago, que al ser admitida a trámite dejó hoy sin efectos el compromiso de no reingresar a Chile en los próximos nueve años (El Comercio Perú, 10 de junio de 2020)

Al admitir la tutela, el Tribunal Superior de Manizales ordenó al Ministerio de Relaciones Exteriores, que a través de la Embajada y el Consulado de Colombia en Quito, de manera inmediata coordine los pormenores necesarios para brindarles a todos los actores atención humanitaria y soporte en vivienda, alimentación, salud y ayuda de emergencia que requieran mientras se da su traslado a nuestro país (El Tiempo, 23 de mayo de 2020)

Los casos descritos por la prensa latinoamericana exponen diversas situaciones conflictivas que los estados de Chile, Colombia y El Salvador experimentaron durante la pandemia, tanto desde la perspectiva de la oportuna asistencia a sus connacionales en la repatriación de salvadoreños y ecuatorianos, mientras que en el caso chileno, imponiendo barreras al posible regreso a Chile en el futuro para aquellos migrantes que retornaban forzosamente a sus países de origen, debido al deterioro de su situación socioeconómica y humanitaria en territorio chileno provocado por el Covid-19 (Abuelafia, 2020; Castillo, 2020; Celis y Aierdi, 2015; Gaete, 2021).

El relato expuesto en este tipo de encuadres noticiosos, muestra una perspectiva humanitaria importante que influye en las noticias redactadas por el quehacer periodístico, las que requieren de un conocimiento importante sobre las instituciones nacionales e internacionales, así como los derechos humanos que están relacionados con los conflictos o crisis migratorios, que permitan exponer a las audiencias adecuadamente el contexto implícito de cada noticia, describiendo fehacientemente las posturas que están en conflicto en cada situación informada.

Asimismo, durante la pandemia muchos gobiernos latinoamericanos decidieron restringir el tránsito de las personas por las fronteras de sus países, ocasionando con ello un agravamiento de la crisis humanitaria generada por los efectos de la crisis sanitaria en la Región:

El vuelo fue con butacas vacías. Podría haber llevado a algunos de los miles de argentinos que están varados en Estados Unidos, pero debido al "cepo" que el gobierno nacional impuso en el aeropuerto de Ezeiza para la llegada de los viajeros postergó, por ahora, el ansiado retorno. La oferta de repatriación 
llegó por parte de la Iglesia de Jesucristo de los Santos de los Últimos Días (Mathus, Soria y Dellacha, 15 de abril de 2020)

El retorno de migrantes venezolanos podría demorar más de seis meses debido a las restricciones impuestas por el régimen de Nicolás Maduro. Agregó que más de 24.000 ciudadanos venezolanos permanecen en el territorio colombiano a la espera de que Venezuela permita la repatriación (El Nacional, 16 de junio de 2020)

Según la prensa latinoamericana, diferentes grupos de ciudadanos denunciaron a sus Estados durante la pandemia, acusando la lenta y escasa respuesta a sus solicitudes de repatriación:

Un grupo de argentinos varados en Madrid envió esta semana una carta abierta a las autoridades gubernamentales, la opinión pública y la sociedad civil en general en la que denuncian una situación de abandono y discuten la mirada que creen que pesa sobre ellos. "No somos un enemigo en contra de la salud pública. No somos una amenaza. Nosotros también estamos en riesgo" (La Nación, 10 de abril de 2020)

Hacemos responsables al Estado colombiano porque no nos ha llegado ningún tipo de respuesta. Solicitamos un vuelo humanitario" [...] "Le estamos pidiendo ayuda a la Embajada y al Ministerio de Relaciones Exteriores, Cancillería para que nos faciliten un vuelo humanitario o un corredor humanitario" (El Tiempo, 17 de mayo de 2020)

Este tipo de medidas claramente se relacionan con la intención de proteger el territorio nacional del contagio por Covid-19, pero dejando en entredicho el debido respeto de los derechos humanos de las personas que quedaron varadas en territorio extranjero deseando retornar a su país de origen (Abuelafia, 2020; Castillo, 2020; Celis y Aierdi, 2015).

La repatriación de los migrantes varados en diferentes países latinoamericanos, produjo una importante tensión diplomática resultado de las medidas que los gobiernos de la Región tomaron para contener el contagio por Covid-19:

Consultado sobre la relación de Uruguay con Venezuela para repatriar a uruguayos que están varados en el país caribeño, Talvi reiteró que con ese país tienen "diferencias políticas", pero no afecta en "nada" para la cooperación humanitaria (El País, 13 de abril de 2020)

El perfil del peruano varado en Venezuela, además, es diferente al de otros países. No son personas que vinieron por turismo, sino a visitar a sus familiares o amigos. Estamos en contacto con la mayoría de ellos y estamos viendo la forma de poderlos apoyar. Lo que se ha hecho es tratar de buscar alternativas para poder llegar al Perú. Lamentablemente, debido a la mala relación bilateral y por la crisis de este país, hasta la fecha no hay ningún vuelo que los pueda llevar. Hemos explorado varias alternativas (Giner, 16 de abril de 2020)

Así, algunos estudios sobre los encuadres utilizados por la prensa internacional como los de Gronemeyer y Porath (2017) o Gonzáles (2016) obtienen un resultado similar al de nuestro estudio. Según Muñiz (2011) otros estudios sobre los encuadres noticiosos de la migración, reconocen al encuadre del conflicto como una de las perspectivas dominantes utilizada por la cobertura periodística sobre dicha problemática social, confirmándose lo observado también para el caso de la repatriación forzada ocurrida en América Latina durante la pandemia por Covid-19.

\subsection{Moralidad}

Respecto de este encuadre, Semetko y Valkenburg (2000) identifican como principales indicadores la existencia de mensajes morales, principios religiosos o prescripciones sociales específicas para el comportamiento humano.

En ese contexto, la prensa mexicana denunció las deportaciones desde Estados Unidos durante la pandemia, generando situaciones migratorias que afectaron los derechos humanos de los deportados: 
Más de 300 centroamericanos hacinados en la sede del Instituto Nacional de Migración (INM) de esta ciudad se amotinaron ayer, para exigir alimentos, atención de salud y repatriación inmediata. Los manifestantes que han sido deportados de Estados Unidos en medio de la emergencia sanitaria internacional por el Covid-19 exigen ser repatriados a su lugar de origen, aun cuando las fronteras de su país han sido cerradas (El Universal, 03 de abril de 2020)

Los representantes legales consultados, sin embargo, coinciden en que los menores de edad deportados no están teniendo acceso al debido proceso y la pandemia está siendo usada como "un pretexto" para que el gobierno de Trump impulse su agenda migratoria "como no había podido hacerlo antes" (El Universal, 02 de junio de 2020)

La repatriación forzada es una expresión tradicional de las políticas migratorias expulsoras implementadas por algunos países (Stang, Lara y Andrade, 2020), lo que de acuerdo con las noticias reseñadas anteriormente exponen un aprovechamiento inapropiado e inhumano del gobierno norteamericano, expulsando migrantes en pleno apogeo de la crisis sanitaria efectuando deportaciones que expusieron a los ciudadanos mexicanos a contagios por el hacinamiento y las deficientes condiciones sanitarias para su deportación.

Otro hecho noticioso destacado por la prensa latinoamericana fueron las dificultades enfrentadas por los venezolanos repatriados, relativa a las condiciones en las que desarrollaron las cuarentenas al regresar a su país:

FundaRedes (ONG de activistas de derechos humanos del vecino país) rechazaron lo que llaman la "improvisación en el manejo de los migrantes forzados retornados que están ingresando al país y son llevados a centros educativos y otras instalaciones sin adecuado suministro de agua potable para cumplir la normativa de la $\underline{\mathrm{OMS}}$, electricidad, sanitarios, seguridad y habitabilidad mínima" (El Tiempo, 11 de abril de 2020)

La Red Venezuela Nariño se pronunció a propósito del retorno voluntario de los venezolanos a su país, pero mostró su inconformidad por la forma en que se desarrolló la actividad, "sin garantías a la protección de derechos humanos de quienes viajan, ni medidas de bioseguridad encaminadas a prevenir el contagio". La organización insistió a las autoridades a buscar nuevas alternativas de asistencia eficaz a la población venezolana y "que su traslado sea realizado en la forma más dignificante y apropiada" (De la Rosa, 13 de abril de 2020)

Asimismo, los ciudadanos venezolanos fueron injustamente acusados de ser armas biológicas que aumentaban el número de contagios en su territorio, por las autoridades de su país:

El gobierno venezolano responsabiliza a diario a las personas que regresan del exterior del aumento de los casos de Covid-19. Día a día hace énfasis en cuántos de los contagios son importados y del país donde provienen [...] los que regresan de manera irregular son considerados "armas biológicas" (La Nación, 07 de agosto de 2020)

La cobertura periodística expuesta anteriormente sobre la situación de los ciudadanos venezolanos en la crisis sanitaria, resalta la importancia que adquieren las relaciones internacionales en la protección de los derechos humanos de los migrantes (Abuelafia, 2020; Castillo, 2020; Gómez-Johnson, 2015), especialmente cuando se trata de migración forzada por situaciones humanitarias como la ocasionada por la pandemia de Covid-19, especialmente respecto de las garantías al acceso de salud de todas las personas como un derecho humano fundamental (Manchola et al., 2017).

Lamentablemente, la repatriación durante la pandemia facilitó el escenario propicio para que redes de tráfico ilegal de personas, aprovecharán la desesperación de quienes deseaban regresar a sus países producto del cierre de fronteras:

Muchos venezolanos ponen en riesgo sus vidas y cruzan la región por pasos ilegales para llegar a Colom- 
bia y de ahí a su país. Esta situación es aprovechada por "coyotes" (personas que transportan de forma ilegal a inmigrantes), que por 15 o 30 dólares los ayudan a pasar de un lado a otro bajo condiciones inhumanas, dado que las fronteras están cerradas por el coronavirus y el flujo del transporte está en mínimos (El Comercio Perú, 24 de mayo de 2020)

Hasta el momento van 12 personas detenidas por estos hechos, entre los que destacan cuatro funcionarios públicos, algunos de ellos médicos, que concretaban estas transacciones a través de la frontera terrestre que el país comparte por el sur con Brasil [...] promovían estos paquetes de viaje a través de redes sociales, fueron detenidos en flagrancia, y se les imputan los delitos de corrupción propia, obtención ilegal de lucro, tráfico ilegal de personas y asociación para delinquir (El Nacional, 10 de septiembre de 2020)

La crisis migratoria generada por la pandemia por Covid-19, se transforma en el escenario propicio para que las mafias de trata de personas aprovecharan la desesperación de los migrantes varados por el cierre de fronteras y la pérdida de sus puestos de trabajo, acrecentando el sufrimiento y la vulneración de los derechos humanos de las personas afectadas por dicho flagelo (Abuelafia, 2020; Celis y Aierdi, 2015; Gaete, 2021).

Además, desde la perspectiva del fenómeno de la migración forzada es importante citar la reflexión de Gómez-Johnson (2015, p.201) quien señala que dicho movimiento de la población “...implican a personas que abandonan sus hogares, forzados por conflictos sociales, persecución o violencia criminal", destacando que a diferencia del estatus jurídico de los refugiados, un migrante forzado es una persona ilegal si cruza las fronteras internacionales y no está protegido por el compromiso de los países de no repatriarlos de regreso a su país de origen mientras estén en peligro.

Lamentablemente, tal y como evidencian los encuadres periodísticos presentados en nuestro estudio, en el caso de la crisis migratoria ocasionado por el Covid-19 ocurrió exactamente como advierte Gómez-Johnson (2015), es decir, personas sin trabajo ni cobertura de salud, intentando infructuosamente cruzar las fronteras cerradas por los gobiernos latinoamericanos, sin certeza de encontrar en sus países de origen el apoyo y los recursos necesarios para enfrentar la pandemia.

\subsection{Interés económico}

En este último encuadre, Semetko y Valkenburg (2000) proponen como principales indicadores para su reconocimiento a la existencia de pérdidas/ganancias financieras o los costos/gastos involucrados con la problemática relacionada con la cobertura informativa.

Según las informaciones periodísticas, la repatriación durante la pandemia generó un importante aumento del gasto público de los estados latinoamericanos, especialmente para materializar vuelos humanitarios:

El mayor gasto lo hizo la Fuerza Aérea, que participó, a pedido de la Cancillería, en tareas de repatriación de más de 350 uruguayos que se encontraban varados en el exterior en plena pandemia [...] Al día de hoy se gastaron en el entorno de US\$ 400.000 en combustible y servicios de aeropuertos en el extranjero, esto incluye desde el reabastecimiento hasta la logística de valijas (El País, 12 de abril de 2020)

La mayor parte del gasto se destinó a los vuelos chárter que contrató el Ministerio de Relaciones Exteriores para trasladar a argentinos que quedaron sin posibilidad de volver por la cancelación masiva de los vuelos. El Estado pagó los viajes, pero reclamará esos montos a las compañías que debían haber prestado el servicio. Hasta ahora, se gastó en este ítem US\$1,5 millones (\$101.600.000 al cambio de hoy). El resto de los gastos se destinó al mantenimiento individual de los argentinos que necesitaban asistencia. La Cancillería estima que se gastaron US\$503.000 (\$34 millones) en medicamentos, alimento y alojamiento (Soria, 23 de abril de 2020)

Las pesquisas periodísticas desarrolladas desde este encuadre son minoritarias durante el período analizado, pero evidencian el enfoque informativo utilizado para apreciar antecedentes sobre el vo- 
lumen de recursos públicos destinados a la repatriación, especialmente en lo relativo a la operación de los vuelos humanitarios realizados durante los primeros meses de la pandemia, pero también sobre aquellos fondos destinados a costear la subsistencia de los migrantes varados que estaban a la espera de abordar un avión que los llevará de regreso a su país de origen, debido a que la mayoría de los gobiernos latinoamericanos debieron aumentar drásticamente el gasto público para enfrentar la crisis sanitaria, siendo importante ofrecer noticias que transparenten información sobre el adecuado uso del presupuesto gubernamental adicional.

\section{Discusión y Conclusiones}

El estudio identifica a la atribución de responsabilidad y el conflicto como los principales encuadres noticiosos utilizados por los periódicos latinoamericanos, de acuerdo con la propuesta de Semetko y Valkenburg (2000), para desarrollar la cobertura informativa durante los primeros meses de la pandemia que permitieron proporcionar información sobre los diferentes aspectos relacionados con la repatriación de migrantes.

En lo relativo al encuadre sobre la atribución de responsabilidad, los medios de comunicación latinoamericanos incluidos en la muestra del estudio, exponen su interés en identificar a aquellos actores individuales o grupales que tienen un rol relevante en los principales aspectos que dan origen o permiten obtener una solución concreta para la repatriación de migrantes durante la pandemia, específicamente respecto del impacto por el cierre de fronteras, así como respecto de la realización de vuelos humanitarios para repatriar a los migrantes varados en el extranjero.

Así por ejemplo, el diario El Mercurio de Chile es el que concentra la mayor cantidad de noticias relacionadas con el encuadre de atribución de responsabilidad, identificando fundamentalmente a las autoridades argentinas y bolivianas como principales responsables de la situación humanitaria de sus connacionales varados en Chile, especialmente por el estricto cierre de fronteras decretado por los gobiernos de ambos países, afectando a miles de sus compatriotas sin poder retornar prontamente a sus países de origen. Además, la mayoría de los diarios que utilizan el encuadre de atribución de responsabilidad concentran las informaciones sobre la repatriación en el rol que cumplen los Cancilleres, Cónsules y Embajadores como actores políticos clave para implementar soluciones efectivas para quienes quedaron varados en el extranjero por el cierre de fronteras.

En ese contexto, durante la emergencia sanitaria la decisión de cerrar las fronteras efectuadas por la mayoría de los países de la Región, como medida para proteger sus territorios de los contagios por Covid-19 fue ampliamente informada por los medios de comunicación, porque afectó a miles de ciudadanos latinoamericanos que por diferentes razones se encontraban fuera de sus países, quienes no pudieron regresar a su lugar de origen a través de las fronteras terrestres, marítimas o aéreas, lo que sumado al deterioro de la situación socioeconómica ocasionó un importante drama humanitario, generando incluso algunos episodios de tensión diplomática entre países tales como Argentina y Chile, o entre Colombia y Venezuela.

Respecto del encuadre de conflicto en las noticias sobre la repatriación durante la pandemia, de acuerdo con Semetko y Valkenburg (2000) ese tipo de informaciones buscan destacar el enfrentamiento o las disputas suscitadas entre los actores protagonistas de las noticias publicadas. Así, los diarios El Nacional de Venezuela y La Nación de Argentina son los medios de prensa incluidos en el estudio que utilizaron mayormente este tipo de encuadre, destacando los conflictos de los presidentes de ambos países con otros gobiernos latinoamericanos, disputas que provocaron algunas tensiones para la diplomacia latinoamericana.

Un aspecto de gran interés para las noticias relacionadas con este encuadre se relaciona con las reacciones de las personas varadas en el extranjero, respecto de las dificultades y cancelaciones 
de los vuelos programados para poder regresar a su país de origen, lo que se tradujo en críticas y manifestaciones de los migrantes hacia sus consulados, como instancia gubernamental más próxima para quienes quedaron varados en el extranjero sin poder cruzar las fronteras durante la crisis humanitaria ocasionada por el covid-19.

Además, el encuadre sobre el conflicto generado por la repatriación forzada de migrantes latinoamericanos durante la pandemia, estuvo estrechamente relacionado con la cobertura informativa proporcionada por los medios de prensa escrita sobre la judicialización de los casos de la repatriación de salvadoreños y colombianos varados en el extranjero, así como la presión que organismos internacionales realizaron sobre varios gobiernos de la Región para que implementaran acciones humanitarias más concretas e inmediatas en los procesos de repatriación forzada.

Finalmente, los efectos de la pandemia de Covid-19 continúan actualmente a nivel mundial, razón por la cual la labor de los medios de comunicación en la cobertura de los hechos noticiosos relacionados con las personas afectadas por la migración forzada serán fundamentales, para prevenir y combatir nuevos abusos y vulneración de sus derechos humanos, que actualmente siguen siendo transgredidos en diferentes fronteras latinoamericanas por traficantes de personas, pero también por parte de algunos gobernantes en los territorios de los países de origen y destino de los flujos migratorios en donde no se garantiza el acceso a la adecuada y oportuna asistencia humanitaria, o a la vacunación contra el coronavirus. Por ende, la proyección de este tipo de estudios sobre los encuadres periodísticos de la migración forzada mantiene una gran relevancia y pertinencia en la sociedad latinoamericana, para examinar los hechos noticiosos y las consecuencias sociales de la crisis sanitaria mientras persista la pandemia de Covid-19.

\section{Bibliografía}

Abuelafia, E. (2020). Migración en la región andina: Impacto de la crisis y expectativas en el mediano plazo. Documento para discusión No IDB-DP-0777, Banco Interamericano de Desarrollo (BID). http://dx.doi.org/10.18235/0002386

Álvarez-Gálvez, J., Plaza, J., Muñiz, J. y Lozano, J. (2014). Aplicación de técnicas de minería de textos al frame analysis: identificando el encuadre textual de la inmigración en la prensa. Estudios sobre el Mensaje Periodístico, 20(2), 919-932. https://doi.org/10.5209/rev_ESMP.2014.v20. $\underline{\mathrm{n} 2.47040}$

Ardévol-Abreu, A. (2015). Framing o teoría del encuadre en comunicación. Orígenes, desarrollo y panorama actual en España. Revista Latina de Comunicación Social, 70, 423-450. http://www. revistalatinacs.org/070/paper/1053/RLCS-paper1053.pdf

Calderón, B. (25 de mayo de 2020). Sala ordena reducir plazo de repatriación de salvadoreños "a uno razonable" y se incluya a todos los que quieren regresar. La Prensa Gráfica. https://www. laprensagrafica.com/elsalvador/Sala-ordena-reducir-plazo-de-repatriacion-de-salvadorenos-a-unorazonable-y-se-incluya-a-todos-los-que-quieren-regresar-20200525-0021.html

Castillo, G. (2020). Migración forzada y procesos de violencia: Los migrantes centroamericanos en su paso por México. Revista Española de Educación Comparada, 35, 14-33. https://doi. org/10.5944/reec.35.2020.25163

Celis, R. y Aierdi, X. (2015). ¿Migración o desplazamiento forzado? Las causas de los movimientos de población a debate. Cuadernos Deusto de Derechos Humanos, Nº81. Bilbao: Universidad de Deusto. http://www.deusto-publicaciones.es/deusto/pdfs/cuadernosdcho/ cuadernosdcho81.pdf 
Comisión Económica para América Latina y el Caribe (CEPAL) (2020). Los efectos del COVID-19: una oportunidad para reafirmar la centralidad de los derechos humanos de las personas migrantes en el desarrollo sostenible. Informes COVID-19. https://repositorio.cepal.org/ bitstream/handle/11362/46353/4/S2000618 es.pdf

Cristti, N., Aruguete, N. y Koziner, N. (2020). Escándalos y silencios: Las noticias políticas delante y detrás del poder. Austral Comunicación, 9(1), 1-19. https://doi.org/10.26422/aucom.2020.0901.aru

De Jesús, L. (03 de septiembre de 2020). Es algo absolutamente cruel: la pesadilla que viven los venezolanos varados en República Dominicana. El Nacional. https://www.elnacional.com/ venezuela/es-algo-absolutamente-cruel-la-pesadilla-que-viven-los-venezolanos-varados-enrepublica-dominicana/

De la Rosa, M. (13 de abril de 2020). 240 venezolanos regresaron a su país en un vuelo humanitario desde Pasto. El Tiempo. https://www.eltiempo.com/colombia/cali/240-venezolanosregresaron-a-su-pais-en-vuelo-humanitario-desde-pasto-483480

El Comercio Perú (24 de mayo de 2020). Los miles de venezolanos desplazados por Sudamérica que están volviendo a su país huyendo del coronavirus. https://elcomercio.pe/mundo/

latinoamerica/coronavirus-venezolanos-desplazados-por-sudamerica-vuelven-a-su-pais-huyendodel-covid-19-venezuela-noticia/?ref=ecr

El Comercio Perú (10 de junio de 2020). Polémica en Chile por repatriar migrantes varados a cambio de que no regresen en 9 años. https://elcomercio.pe/mundo/latinoamerica/coronavirusen-chile-colombia-polemica-por-repatriar-migrantes-colombianos-varados-a-cambio-que-noregresen-en-9-anos-covid-19-nndc-noticia/?ref=ecr

El Comercio Perú (30 de junio de 2020). Coronavirus: Gobierno anuncia que más de mil peruanos retornarán al país desde Chile esta semana. https://elcomercio.pe/mundo/actualidad/coronavirusgobierno-anuncia-que-mas-de-mil-peruanos-retornaran-al-pais-desde-chile-esta-semana-covid-19$\underline{\text { nndc-noticia/?ref }=\text { ecr }}$

El Nacional (16 de junio de 2020). Migración Colombia alerta que el retorno de venezolanos podría llevar más de 6 meses. https://www.elnacional.com/mundo/migracion-colombia-alerta-queel-retorno-de-venezolanos-podria-llevar-mas-de-6-meses/

El Nacional (10 de septiembre de 2020). Desmantelaron red que ofrecía repatriación a Venezuela desde EE.UU. https://www.elnacional.com/venezuela/desmantelaron-red-que-ofrecia-repatriacion$\underline{\text { a-venezuela-desde-ee-uu/ }}$

El Nacional (10 de septiembre de 2020). OEA pidió a la comunidad internacional visibilizar la situación de los venezolanos varados. https://www.elnacional.com/mundo/oea-pidio-a-lacomunidad-internacional-visibilizar-la-situacion-de-los-venezolanos-varados/

El Nacional (21 de septiembre de 2020). El régimen autorizó tres vuelos para venezolanos varados en Panamá este lunes. https://www.elnacional.com/venezuela/el-regimen-autorizo-tresvuelos-para-venezolanos-varados-en-panama-este-lunes/

El Tiempo (11 de abril de 2020). Venezolanos: más de 2500 han vuelto a su país en decenas de buses. https://www.eltiempo.com/unidad-investigativa/venezolanos-mas-de-2-500-han-vuelto-asu-pais-en-decenas-de-buses-483198

El Tiempo (17 de mayo de 2020). El feliz retorno de 130 colombianos que estuvieron atrapados en India. https://www.eltiempo.com/colombia/cali/cronica-de-la-felicidad-del-retorno-desde-india-acolombia-496190 
El Tiempo (23 de mayo de 2020). Manizaleños atrapados en Ecuador interpusieron tutela para regresar. https://www.eltiempo.com/colombia/tribunal-ordena-brindar-atencion-a-familiamanizalena-atrapada-en-ecuador-498772

El País (12 de abril de 2020). Analizan instalar un hospital de campaña en unidad del Ejército por el coronavirus. https:/www.elpais.com.uy/informacion/politica/analizan-instalar-hospitalcampana-unidad-ejercito-coronavirus.html

El País (13 de abril de 2020). Gobierno extiende la operación "Todos en casa" para repatriar a 620 uruguayos varados. https://www.elpais.com.uy/informacion/politica/gobierno-extiende-operacionrepatriacion-quizas-mes-dijo-talvi.html

El Universal (02 de junio de 2020). Las silenciosas tácticas para expulsar de EU a más de 900 menores migrantes por el Covid-19. https:/www.eluniversal.com.mx/mundo/coronavirus-las$\underline{\text { silenciosas-tacticas-para-expulsar-de-eu-mas-de-900-menores-migrantes-por-el }}$

El Universal (25 de abril de 2020). Continúa repatriación de mexicanos varados por coronavirus. https://www.eluniversal.com.mx/nacion/coronavirus-continua-repatriacion-de-mexicanos-varados

El Universal (03 de abril de 2020). Se amotinan 300 migrantes y exigen ser repatriados. https:// www.eluniversal.com.mx/estados/se-amotinan-300-migrantes-y-exigen-ser-repatriados

Entman, R. (1993). Framing: Toward clarification of a fractured paradigm. Journal of Communication, 43(4), 51-58. https://doi.org/10.1111/j.1460-2466.1993.tb01304.x

Fernández, C. y Corral, A. (2016). La representación mediática del inmigrante magrebí en España durante la crisis económica (2010-2011). Migraciones Internacionales, 8(4), 73-103. https://www. redalyc.org/pdf/151/15146709003.pdf

Flores, D. (19 de agosto de 2020). ¿Cuánto deben pagar los venezolanos varados en Argentina para regresar en el vuelo de repatriación del régimen? El Nacional. https://www.elnacional.com/ mundo/cuanto-deben-pagar-los-venezolanos-varados-en-argentina-para-regresar-en-el-vuelo-derepatriacion-del-regimen/

Gaete, R. (2021). Encuadres periodísticos de la repatriación de migrantes latinoamericanos residentes en Chile durante la pandemia. Estudios sobre el Mensaje Periodístico, 27(1), 133-144. https://dx.doi.org/10.5209/esmp.71435

Giménez, P. y Berganza, M. (2009). Género y medios de comunicación. Un análisis desde la objetividad y la Teoría del Framing. Madrid: Fragua.

Giner, R. (16 de abril de 2020). Cónsul del Perú en Caracas: "Hemos explorado diversas modalidades de repatriación pero todas se han caído. El Comercio. https://elcomercio.pe/mundo/ venezuela/coronavirus-en-venezuela-covid-19-consul-del-peru-en-caracas-hemos-exploradodiversas-modalidades-de-repatriacion-pero-todas-se-han-caido-pandemia-cuarentena-peruanosvarados-noticia/?ref=ecr

Gómez-Johnson, C. (2015). De la migración económica a la migración forzada por el incremento de la violencia en El Salvador y México. Estudios Politicos, 47, 199-220. http://www.scielo.org. co/pdf/espo/n47/n47a12.pdf

Gonzáles, C. (2016). Las relaciones internacionales del Perú a través del diario Perú 21. Encuadres noticiosos en la información periodística sobre asuntos de Cancillería. Revista Correspondencia \& Análisis, 6, 1-14. http://portal.amelica.org/ameli/ jatsRepo/138/138726014/138726014.pdf 
Gronemeyer, M. (2017). El testeo de instrumentos de análisis de encuadres periodísticos en seis diarios chilenos. Chasqui Revista Latinoamericana de Comunicación, 135, 401-418. https:// repositorio.flacsoandes.edu.ec/bitstream/10469/13259/1/REXTN-Ch135-23-Gronemeyer.pdf

Gronemeyer, M. y Porath, W. (2017). Framing political news in the Chilean press: The persistence of the conflict Frame. International Journal of Communication, 11, 2940-2963. https://repositorio.uc.cl/xmlui/bitstream/handle/11534/22572/Framing\%20political\%20news. pdf? sequence $=2$

Hernández, F. (09 de mayo de 2020). Sala da ultimátum al Gobierno para repatriar varados. $L a$ Prensa Gráfica. https://www.laprensagrafica.com/elsalvador/Sala-da-ultimatum-a-Gobierno-pararepatriar--varados-20200508-0091.html

Koziner, N. (2013). Antecedentes y fundamentos de la teoría del framing en comunicación. Austral Comunicación, 2(1), 1-25. https://doi.org/10.26422/aucom.2013.0201.koz

La Nación (10 de abril de 2020). Varados en Madrid. "Por favor, solo queremos volver a casa". https://www.google.cl/amp/s/www.lanacion.com.ar/economia/carta-abierta-varados-madridhemos-sido-dejados-nid2352886/amp

La Nación (07 de agosto de 2020). "Bioterroristas". La fobia contra los retornados, otro drama de la pandemia. https://www.google.cl/amp/s/www.lanacion.com.ar/sociedad/bioterroristas-la-fobiaretornados-otro-drama-pandemia-nid2415081/amp

La Prensa Gráfica (27 de julio de 2020). La Comisión Interamericana de Derechos Humanos exige al Gobierno de El Salvador información urgente sobre la situación de los varados salvadoreños. https://www.laprensagrafica.com/elsalvador/La-Comision-Interamericana-deDerechos-Humanos-exige-al-Gobierno-de-El-Salvador-informacion-urgente-sobre-la-situacionde-varados-salvadorenos-20200727-0041.html

Manchola, C.; Garrafa, V.; Cunha, T.; y Hellmann, F. (2017). El acceso a la salud como derecho humano en políticas internacionales: reflexiones críticas y desafíos contemporáneos. Revista Ciencia \& Saúde Colectiva, 22(7), 2151-2160. https://www.scielo.br/pdf/csc/v22n7/1413-8123csc-22-07-2151.pdf

Márquez, H. y Delgado, R. (2011). Una perspectiva desde el sur sobre el capital global, migración forzada y desarrollo alternativo. Migración y Desarrollo 9(16), 3-24. http://www.scielo.org.mx/ pdf/myd/v9n16/v9n16a1.pdf

Matarín, E. (2020). Inmigración y COVID-19: Análisis de los informativos en televisión durante la pandemia. Methaodos Revista de Ciencias Sociales, 8(2), 288-304. https://doi. org/10.17502/mrcs.v8i2.412

Mathus, R.; Soria, A. y Dellacha, D. (15 de abril de 2020). Coronavirus: el vuelo de repatriación desde EE.UU. que Gobierno rechazó. La Nación. https://www.lanacion.com.ar/politica/ coronavirus-pedido-ayuda-argentinos-perdieron-vuelo-repatriacion-nid2354053

Mukhortikova, T. (2018). Estudio cualitativo de la metáfora como vehículo de encuadre en los textos noticiosos sobre los atentados del 11-m (El País, The Guardian e Izvestia). Revista de Comunicación, 17(2), 208-228. http://dx.doi.org/10.26441/RC17.2-2018-A9

Muñiz, C. (2011). Encuadres noticiosos sobre migración en la prensa digital mexicana. Un análisis de contenido exploratorio desde la teoría del framing. Convergencia, 55, 213-239. http:// www.scielo.org.mx/pdf/conver/v18n55/v18n55a9.pdf 
Organización Internacional para las Migraciones (OIM) (2019). Glosario de la OIM sobre migración. Derecho Internacional sobre Migración N³4. https://publications.iom.int/system/files/ pdf/iml-34-glossary-es.pdf

Organización Internacional para las Migraciones (OIM) (2020). Covid-19 impact on stranded migrants. Return Task Force. https://www.iom.int/sites/default/files/documents/issue brief return task force.pdf

Ortiz, R. y Stable, Y. (2021). Evolución y tendencias de la investigación en comunicación sobre epidemias y pandemias en el ámbito internacional. Revista de Comunicación, 20(1), 175-196. https://doi.org/10.26441/RC20.1-2021-A10

Peña, J. (03 de junio de 2020). Las Condes y Recoleta albergarán a inmigrantes que acampan fuera del consulado boliviano. EMOL. https://www.emol.com/noticias/ Nacional/2020/06/03/988014/Las-Condes-albergara-bolivianos.html

Quintero, R. (17 de mayo de 2020). La odisea para traer a 366 colombianos varados al otro lado del mundo. El Tiempo. https://www.eltiempo.com/mundo/mas-regiones/coronavirus-repatriacionde-366-colombianos-varados-en-el-sudeste-asiatico-496364

Reyes, C. (03 de junio de 2020). Los colombianos acampan afuera de una embajada esperando un vuelo. El Tiempo. https://www.eltiempo.com/mundo/latinoamerica/coronavirus-colombianosacampan-frente-a-la-embajada-chilena-esperan-un-vuelo-502554

Romero, M. (06 de abril de 2020). Países de PROSUR acuerdan colaborar en la compra de equipos médicos en medio de "guerra" por insumos. EMOL.

https://www.emol.com/noticias/Nacional/2020/04/06/982276/Prosur-acuerda--colaborar-compra.html

Semetko, H. y Valkenburg, P. (2000). Framing European politics: a content analysis of press and television news. Journal of Communication, 50(2), 93-109. https://doi. org/10.1111/j.1460-2466.2000.tb02843.x

Soria, A. (22 de abril de 2020). Coronavirus en la Argentina: repatriaron al 89\% de los varados, pero quedan otros 21.493 argentinos en 82 países. La Nación. https://www.google.cl/amp/s/www. lanacion.com.ar/politica/el-gobierno-aun-debe-repatriar-21493-argentinos-nid2356881/amp

Soria, A. (23 de abril de 2020). Coronavirus en la Argentina: la Cancillería gastó \$135 millones para repatriar y asistir a los argentinos varados en situación vulnerable. La Nación. https://www. google.cl/amp/s/www.lanacion.com.ar/politica/la-cancilleria-gasto-135-millones-repatriar-asistirnid2357365/amp

Stang, F.; Lara, A. y Andrade, M. (2020). Retórica humanitaria y expulsabilidad: migrantes haitianos y gobernabilidad migratoria en Chile. Si Somos Americanos Revista de Estudios Transfronterizos, 20(1), 176-201. http://dx.doi.org/10.4067/S0719-09482020000100176

Stefoni, C. y Brito, S. (2019). Migraciones y migrantes en los medios de prensa en Chile: La delicada relación entre las políticas de control y los procesos de racionalización. Revista de Historia Social y de las Mentalidades, 23(2), 1-28. https://www.rhistoria.usach.cl/sites/ revistahistoria/files/document.pdf

Suárez, E. (22 de mayo de 2020). Coronavirus en Perú: más de 1.500 peruanos varados en Arica serán repatriados desde mañana. El Comercio Perú. https://elcomercio.pe/peru/tacna/ coronavirus-en-peru-mas-de-1500-peruanos-varados-en-arica-seran-repatriados-desde-manana$\underline{\text { noticia/?ref }=\text { ecr }}$ 
Valera, L. (2016). El sesgo mediocéntrico del framing en España: una revisión crítica de la aplicación de la teoría del encuadre en los estudios de comunicación. ZER, 21(41), 13-31. https:// ojs.ehu.eus/index.php/Zer/article/view/17259/0

Vargas, F. (08 de junio de 2020). Canciller boliviana valora acercamientos diplomáticas con Chile y agradece gestiones de repatriación en pandemia. EMOL. https://www.emol.com/noticias/ Nacional/2020/06/08/988517/Canciller-Bolivia-Pandemia.html 